\title{
|||||||||||||||||||||||||||||||||||||||||||||||||||||||||||||||||||.
}

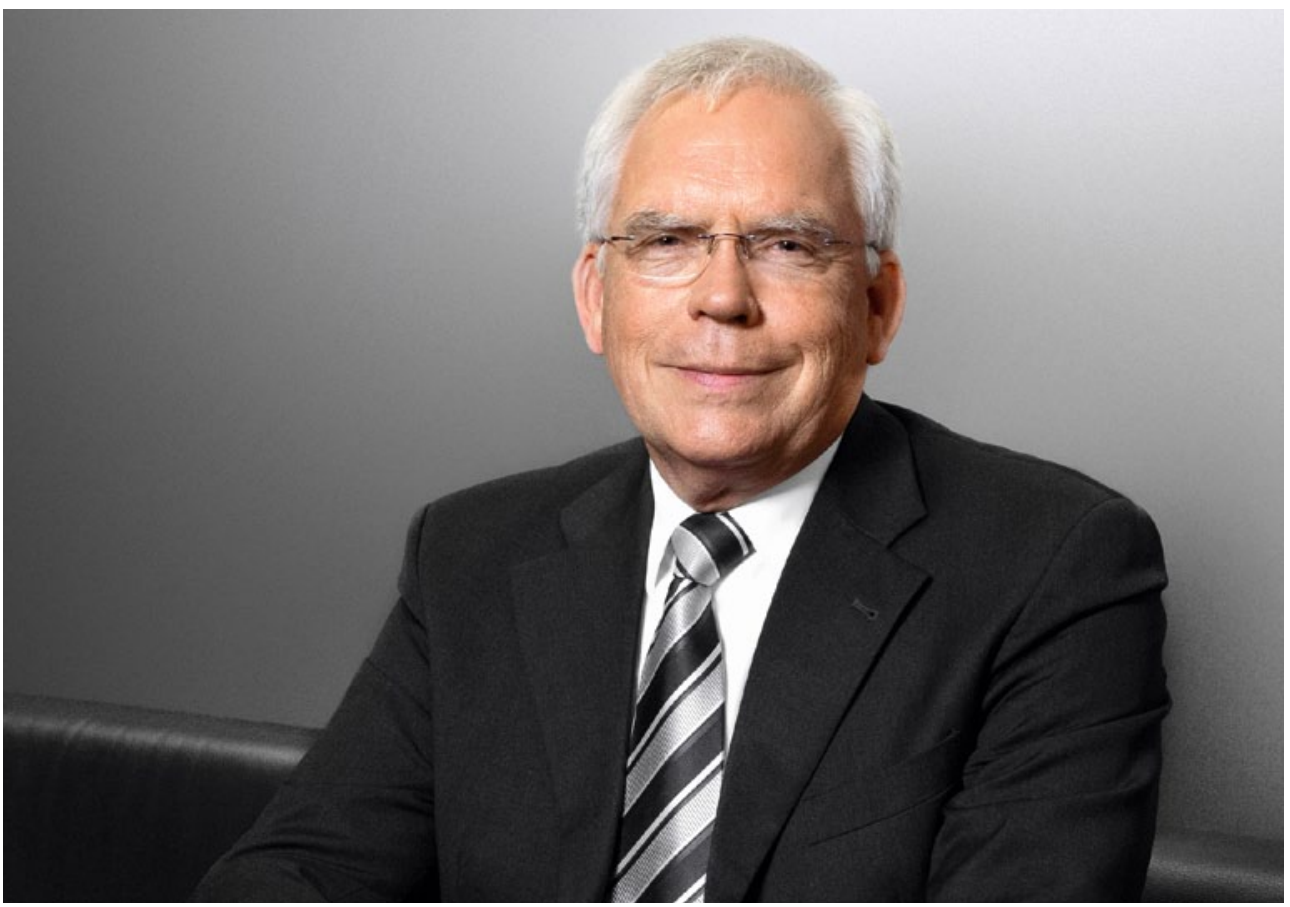

PROF. DR.-ING.

ULRICH HACKENBERG

Mitglied des Vorstands und

verantwortlich für die Technische

Entwicklung, Audi AG

\section{UNTERWEGS IN DIE ZUKUNFT}

Noch vielfältiger, noch vernetzter und nachhaltiger - so sieht Audi die Mobilität der Zukunft. Und daran arbeiten bei uns weltweit mehr als 10.000 Entwickler. Zum Jahresauftakt haben wir auf den Branchenmessen in Las Vegas und Detroit gezeigt, mit welchen Produkten und Technologien wir Mobilität neu definieren. Ich freue mich sehr über die Resonanz: Wir wurden mehrfach als Innovationstreiber unserer Industrie ausgezeichnet.

Einen Meilenstein setzen wir Mitte des Jahres, wenn der Audi A3 e-tron auf den Markt kommt. Wir erweitern die dritte Generation der erfolgreichen Kompaktfamilie um den stärksten Plug-in-Hybrid-Antrieb ihrer Klasse. Mit ihm erfüllen wir die Erwartungen unserer Kunden an alternative Antriebe, indem wir kompromisslos auf Leistung, Reichweite und Effizienz setzen.

Im A3 e-tron arbeitet ein 1,4-1-TFSI-Ottomotor mit $110 \mathrm{~kW}$ zusammen mit einem 75-kW-Elektromotor. Daraus resultiert eine Systemleistung von 150 kW. Den Spurt auf Tempo 100 absolviert der A3 e-tron in 7,6 s und erreicht $222 \mathrm{~km} / \mathrm{h}$ Spitze. Der Normverbrauch liegt bei 1,5 l pro $100 \mathrm{~km}$. Im Alltag kann man den Wagen dank der elektrischen Reichweite von bis zu $50 \mathrm{~km}$ als reines E-Auto nutzen. Darüber hinaus bietet der Hybridmodus weitere $890 \mathrm{~km}$ Aktionsradius und somit uneingeschränkte Mobilität.

Die gesamte Audi-A3-Familie basiert auf dem Modularen Querbaukasten (MQB) - einem wettbewerbsüberlegenen Werkzeug, um zahlreiche Modelle des Volkswagen-Konzerns effi- zient zu entwickeln und zu produzieren. Dank der Modulbauweise, die ihren Anfang mit dem Modularen Längsbaukasten (MLB) bei Audi nahm, können wir in allen dafür ausgelegten Werken hochflexibel produzieren. Ob TFSI-, TDI-, Front- oder Quattro-Antrieb, ob e-tron oder g-tron: Je nach Marktanforderung bauen wir die verschiedenen Varianten auf ein und derselben Fertigungslinie. Konzernweit lassen sich auf Basis des MQB bis zu 40 Modelle mit alternativen Antrieben ableiten. Somit bringen wir Spitzentechnologien schnell und breit gefächert zu unseren Kunden. Eine mögliche Variante des MQB mit E-Antrieb zeigt das Showcar Audi allroad shooting brake. Dabei kombinieren wir einen Plug-in-Antrieb an der Vorderachse mit einem E-Motor an der Hinterachse zu einem elektrischen Allradantrieb mit $300 \mathrm{~kW}$ Systemleistung.

Die Logik der Modulbauweise führen wir demnächst mit der zweiten Generation des MLB fort. Darauf basieren alle Modelle ab Audi A4 aufwärts, bei denen die Motoren längs verbaut sind. Für die e-tron-Variante setzen wir einen leistungsstarken E-Motor ins Getriebe und nutzen eine neue Generation des mechanischen Quattro-Antriebs. Wir kombinieren also die e-tron-Technik mit den Vorzügen des permanenten Allradantriebs, einem Kernwert unserer Marke.

Aus solchen Ideen und unserer Innovationstradition entstehen nachhaltige Produkte für die Mobilität von morgen. Für mich als langjährigen Audianer mit einer Entwicklerbiografie von rund drei Jahrzehnten ist das immer wieder aufs Neue faszinierend. 